\title{
Marketing Mix in Team Sports in Serbia
}

\author{
Radenko M. Matic ${ }^{1}$, Nebojsa Maksimovic ${ }^{1}$, Jovan Vukovic ${ }^{1}$, Dusan Corilic ${ }^{1}$, Rajko Bujkovic ${ }^{2}$, Damjan Jaksic ${ }^{1}$ \\ 'University of Novi Sad, Faculty of Sport and Physical Education, Novi Sad, Serbia \\ ${ }^{2}$ Mediterranean University Montenegro, Faculty of Business Studies, Podgorica, Montenegro
}

\begin{abstract}
Marketing activities, i.e. promotional presentations of various offers to a wide audience, represent inevitable means in strategic plans of organisations from various fields. Such approach also demands from sports organisations to form a promotional marketing mix. The objective of this paper was to examine the marketing mix in sports clubs of sports teams at the highest competition ranking in Serbia. A sample of 118 examinees - available managers from four collective sports management teams (football, basketball, handball and volleyball), was used for conducting an assessment of attitudes regarding the use of the marketing mix. Obtained results show a low current status of marketing in the assessed sports, and by implementing the Kruskal Wallis and Man Whitney tests, differences in certain elements of the marketing mix were also recognised. These differences indicate the advantage on the side of the managers working in football and basketball field as opposed to those working with handball and volleyball. Ultimately, theoretical and practical values of the obtained results were also discussed.
\end{abstract}

Key words: Sport Product, Marketing, Strategy, Collective Sports, Sports Clubs

\section{Introduction}

Unlike foreign authors, only few authors in domestic academic circles examine sports marketing. All of the aforementioned has partly caused the low quantum of theoretical and practical knowledge in the discipline in the domain of domestic sport. Indications are also given by the authors Maksimović and Raič (2007) claiming that in our sports practice a very narrow and wrong understanding of marketing has been accepted which gives sense to it as to an additional commercial activity of a sports club focused on "obtaining money". Such understanding of the marketing discipline significantly aggravates an integral, holistic approach to marketing in the strategic planning of sports organisations. Such approach deals with the current and potential purchasers interested in the offer of the sports organisations, as well as the products and services associated with sport (Gašović, 2005). Clear focus on the consumer in the concept of sports marketing is consisted of the activities designed for the purpose of satisfying the needs and wishes of the consumers for sports products and services (Shilbury, Westerbeek, Quick, \& Funk, 2009; Gašović, 2011). These activities are realised through the exchange processes (Mullin, Hardy, \& Sutton 2007), and such orientation according to Popovic (2017) requires from human resources in sport to follow the "pulse" of all stakeholders surrounding the sports events.

In order to have the sports products and services presented in the best possible way to potential consumers, it is necessary that every organisation defines its sports promotional marketing mix. The marketing mix concept was first developed in 1950s at the Harvard University by Neil Borden. Borden (1964) made a list of 12 elements a producer must consider while planning the marketing. The list is simplified and modified by Eugene McCarthy until designing the widely used marketing mix, i.e. 4P model: product, place, price and promotion. The four elements take a significant position in the business strategies and the marketing concepts of a number of organisations. Over time, the model has lived to see an addition of the fifth element - human resources in the findings of many marketing researchers.

Grubor (2009) suggests that creating value includes first three elements (determining the characteristics of the service offer, setting the price and deciding on the service distribution), while the value delivery requires hiring service staff, i.e. realisation of the service promotion in the form of the sale improvement, service

\section{Correspondence:}

\section{Montenegro} Sport
R. M. Matic

University of Novi Sad, Faculty of Sport and Physical Education, Lovcenska 16, 21000 Novi Sad, Serbia

E-mail: radenkomatic@uns.ac.rs 
propaganda (remaining two elements of the marketing mix). On the other hand, Jobber (2006) states that three significant conditions are important for meeting the marketing concept: focus on purchasers, integrated efforts and meeting the objectives.

In the field of sport, Maksimović and Raič (2012) explain the marketing mix by emphasising that "the purchaser is in the centre of the marketing activity in sport for whose interest and needs the sports organisation develops and forms its product-service, forms its price, finds most favourable delivery (distribution) channels to the user at the right moment and the right place, followed by the most effective presentation (promotion) and with the specially trained service staff. "Sports organisation is perceived as the service firm which can meet its objective provide it successfully combines (mixed) these elements. According to these authors, marketing mix in sports organisations relies on five marketing elements (5P).

In his approach to the marketing mix of sports organisations, Gašović (2009) differentiates among the following elements: sports offer, price and publicity and public relations. According to the same author, the main function of the communication strategy is presenting the sports offer that shall satisfy certain needs of the stakeholders in the sports market (Gašović, 2011). As part of the sports offer, the author differentiates among four levels: sports experience, sports event, sports result, image of sports clubs or individual athletes and a sports brand. Tomić (2001), presents segmentation of sports results as the product by giving division in the following units: 1) club image, 2) sports brand, 3) sports event, 4) sports services and 5) image of an athlete or the entire team, while other researches confirm the connection between the sports competitive results driven by motivating and identifying the spectators with the team (Milne \& McDonald, 1999).

Therefore, it is clear that the sports product is composed of tangible or material (sports facilities, players, etc.) and intangible or immaterial elements (spectators' impression, etc.). Naturally, intangible elements complicate the implementation of marketing. Grubor (2010) also talks about this and states the differences in production and consumption of physically tangible products when compared to the services and the fact that the service marketing implementation is actually more complex in relation to the marketing implementation of physically tangible products.

Maksimović and Raič (2007) emphasise the need for a marketing approach in solving problems seen in old or European sports. Authors identify the crisis in such sports, concurrently identifying the difficulty of adapting such sports to the changed surroundings as the main cause. Moreover, Tomic (2001) advocates his own approach, but also mentions that one should be very careful when implementing the marketing concept, i.e. bad sides of and uncritical copying of the principle from the American sports should be considered, where marketing is most developed both in theory and in practice. Furthermore, maximum of the own system appreciation should exist, but also approach to the mission and sports development, as well as to the personal economical and social development. Andref (2001) also indicates the bad sides of such changes in sport due to the overstressed commercialisation of sports, who also recognises that the placement of the big business capital in sport has led to the loss of the ethical sports perspective, i.e. overemphasised spectacularity when compared to the sports values.

The objective of this paper is examining the marketing mix in sports clubs practising team sports with the highest competitive ranking in Serbia.

\section{Methods}

The sample of examinees in this research was consisted of 118 available managers from various levels of organisational structure of sports organisations from four selected collective sports (football, basketball, handball and volleyball), which institutionally belong to the highest competition rank. The following parties are covered by surveys as part of each sports organisation-club: management representatives (president, secretary, etc.), middle managers (marketing sector, finances, etc.), expert staff representatives and leaders of first competition teams. Namely, these are the managers whose work is crucial for implementing the management marketing concept in sports clubs. Table 1 shows the socio-demographic properties of the examinees.

Table 1. Socio-demographic properties of the examinees sample

\begin{tabular}{|c|c|c|c|}
\hline Variables & & $\mathbf{N}$ & $\%$ \\
\hline \multirow{2}{*}{ Sex } & Male & 101 & $(85.5 \%)$ \\
\hline & Female & 17 & $(14.5 \%)$ \\
\hline \multirow[t]{3}{*}{ Age } & $\mathrm{AS}=43,49 \mathrm{SD}=10,1$ & & \\
\hline & Primary & 0 & 0 \\
\hline & Secondary & 23 & 20.0 \\
\hline \multirow{6}{*}{ Education } & College & 29 & 25.2 \\
\hline & Bachelor & 56 & 48.7 \\
\hline & Master & 7 & 6.1 \\
\hline & $\mathrm{PhD}$ & 0 & 0 \\
\hline & Sport and physical education & 30 & 40.5 \\
\hline & Economics & 18 & 24.3 \\
\hline \multirow[t]{5}{*}{ Qualifications } & Business/ass. diploma & 12 & 16.2 \\
\hline & Diploma in the marketing field & 12 & 16.2 \\
\hline & Certificate in the marketing field & 2 & 2.7 \\
\hline & Municipal & 4 & 4.9 \\
\hline & District & 4 & 4.9 \\
\hline \multirow{4}{*}{ Former sports status } & Provincial & 11 & 13.4 \\
\hline & Republic & 33 & 40.2 \\
\hline & International in the state & 12 & 14.6 \\
\hline & International abroad & 18 & 22.0 \\
\hline
\end{tabular}


(continued from previous page)

\begin{tabular}{llcc}
\hline Variables & & $\mathbf{N}$ & $\%$ \\
\hline & Junior team coach & 12 & 10.5 \\
& First team coach & 15 & 13.2 \\
Role/position & Club secretary & 27 & 23.7 \\
in the club & Accounting manager/teller & 0 & 0 \\
management & Club manager & 20 & 17.5 \\
& Club president & 6 & 5.3 \\
& Head of the marketing department & 7 & 6.1 \\
\hline
\end{tabular}

The reasearch covered $85.5 \%$ male examinees, i.e. $14.5 \%$ female examinees. Majority of examinees had Serbian nationality $(95.3 \%)$, followed by Montenegrin and Bosnian nationality (1.9\% each). Almost half of the sample examinees had higher education degrees (48.7\%). As we were analysing the higher levels of education (reference to the examinees with magisterial or Master's degrees), it can be stated that the level of education degree is recognised in $6.1 \%$ examinees, whereas none of the examinees had the $\mathrm{PhD}$ degree. Moving on to the lower education levels, we noticed that $20 \%$ of examinees had secondary education, and $25.2 \%$ had a college degree. Qualifications in the field of sports and physical education were identified in $40.5 \%$ of examinees, and in the field of economics the percentage was $24.3 \%$ out of all examinees. Qualifications in business or marketing were identified in $16.2 \%$ of examinees.

As for the previous sport status, examinees with the experience in competitions from the republic rank sport prevail $(40.2 \%)$, followed by the examinees with international experience (from abroad $22.0 \%$, and/or in the country $14.6 \%$ ). Provincial level of competitions was reached by $13.4 \%$ of examinees, whereas the municipal and zone level was reached by $4.9 \%$ of examinees. Majority of the surveyed people hold the positions of the club secretary (23.7\%) and the club managers $(17.5 \%)$. With respect to trainers (juniors and first team), $23.7 \%$ examinees were covered. The least number of examinees were represented by the club presidents $(5.3 \%)$ and heads of the marketing department (6.1\%). Most examinees received their professional qualifications at the faculties from the field of sport and physical education (40.54\%), and then from the field of economics $(24.32 \%)$.

The number of clubs per sports which took part in the survey was the following: football -12 , basketball -10 , handball -10 and volleyball - 12 clubs. Operationalisation of researches referred to supplying the survey to the managers in sports organisations in one of the two suggested ways: 1) as the survey with the use of electronic survey version, and 2) as the printed version of the survey for the management representatives in the sports clubs. Employees working in the sports clubs and/ or the examinees independently chose their preferable ways of participation in the research. In order to ensure the best possible treatment of the research in sports clubs, most of the questionnaires were forwarded across the suitable associations and companies in the respective sports fields. This way, distribution of questionnaires in the volleyball clubs was conducted with the assistance of the Association of the first league volleyball clubs, in basketball it was conducted through the Basketball Union of Vojvodina and in football, through the Serbia Community of Super League Football Clubs.

All the questions regarding the elements of the marketing mix in sports clubs considered answers in the 1-5 Likert scale, whereas the statistical interpretation of data covered the Kruskal Wallis test and the Man Whitney test.

\section{Results}

Results analysis primarily included determining to what level were the examinees familiar with the marketing concept and to what level their organisation uses $4 \mathrm{P}$ combination of marketing variables, as presented in Table 2.

Table 2. Differences in sports in comprehending and implementing the marketing concept (\%)

\begin{tabular}{lccccccccc}
\hline \multirow{2}{*}{ Marketing mix } & \multicolumn{2}{c}{ Football } & \multicolumn{2}{c}{ Basketball } & \multicolumn{2}{c}{ Handball } & \multicolumn{2}{c}{ Volleyball } & \multirow{2}{*}{$\boldsymbol{X}^{2}$} \\
& Yes & No & Yes & No & Yes & No & Yes & No & \\
\hline Are you familiar with the marketing mix concept? (\%) & 65.7 & 34.3 & 86.2 & 13.8 & 48 & 52 & 45 & 55 & $12.04^{* * *}$ \\
Does your organisation use 4P? (\%) & 58.8 & 41.2 & 44.8 & 55.2 & 24 & 76 & 10 & 90 & $15.57^{* *}$ \\
\hline
\end{tabular}

An interesting piece of information would be that the football managers were less familiar with the marketing concept than the ones in basketball $(65.7 \%$ in football as opposed to $86.2 \%$ in basketball). Nevertheless, it is noticeable that in football and basketball there is a higher percentage of examinees with the knowledge in the marketing concept as opposed to the ones in volleyball and handball which proved itself to be statistically significant. It can be observed that such results were caused by a somewhat better market position of the afoementioned sports in Serbia. Nevertheless, additional information on the implementation of the 4P marketing mix model, has shown that its understanding does not entail its necessary implementation. If we exclude the football clubs and partly basketball clubs, there is a noticeable decrease in the percentage of the $4 \mathrm{P}$ marketing mix implementation in other sports.

Obtained results show that more than a half of the examined clubs had no marketing sectors divided in departments (51.28\%), which speaks about the insufficient area for the marketing field in the clubs business strategy. The examinees most often mentioned economic reasons to explain the non-existent specialised department. What can be considered as bad result is that almost $1 / 4$ of examinees $(22.22 \%)$ believed that the marketing department was not formed due to the lack of interest. Such result speaks in favour of the insufficient recognition of the marketing relevance. Moreover, if we observe the marketing status in football clubs (Table 3 ), it can be noticed that 
majority of examinees equalise it with the finances in the clubs and a bit fewer of examinees associate it with administration or the secretariat, i.e. it holds higher ranking than the safety segment and ticket sale. As opposed to football, marketing status in the handball clubs is according to the majority of examinees equalised with the ticket sale sector and/or safety. Furthermore, around a half of the examinees believes that marketing is on the same level as players, team management and club administration. Lower status of marketing when compared to the club management is noticeable in over $50 \%$ of examinees in football and volleyball, whereas in basketball it is even more stressed in favour of team management (70.4\%).

Table 3. Marketing/commercial function status based on other functions per sports (\%)

\begin{tabular}{lcccccccccccc}
\hline Sport & \multicolumn{3}{c}{ Football } & \multicolumn{3}{c}{ Basketball } & \multicolumn{3}{c}{ Handball } & \multicolumn{3}{c}{ Volleyball } \\
\hline Marketing status & lower & same & higher & lower & same & higher & lower & same & higher & lower & same & higher \\
\hline Players & 57.1 & 34.3 & 8.6 & 85.2 & 11.1 & 3.7 & 55.6 & 27.8 & 16.7 & 41.7 & 50.0 & 8.3 \\
Team management & 55.9 & 35.3 & 8.8 & 70.4 & 22.2 & 7.4 & 55.6 & 44.4 & 0 & 16.7 & 54.2 & 29.2 \\
Administration/secretary & 48.5 & 18.2 & 33.3 & 40.7 & 40.7 & 18.5 & 38.9 & 50.0 & 11.1 & 17.4 & 52.2 & 30.4 \\
Finances & 18.2 & 69.7 & 12.1 & 40.7 & 51.9 & 7.4 & 66.7 & 33.3 & 0 & 20.8 & 41.7 & 37.5 \\
Ticket sale & 8.8 & 11.8 & 79.4 & 25.9 & 37.0 & 37.0 & 44.4 & 27.8 & 27.8 & 25.0 & 70.8 & 4.2 \\
Safety/economic department & 0 & 17.6 & 82.4 & 7.4 & 44.4 & 48.1 & 50.3 & 33.3 & 16.7 & 8.3 & 79.2 & 12.5 \\
\hline
\end{tabular}

Also, interpretation of results referred to a display of descriptive characteristics of sports organisations developed according to the elements of the marketing mix (people, place, promotion, distribution, product).

People. It is noticeable that a prominent part of the marketing role is taken by the managing structures in the club management, who use their connections to ensure assistance in the form of finances, material means and human resources. Such result derives from the lack of the marketing sector in nearly half of the examined sports organisations, dependence of the marketing sector, as well as the manner of the marketing department management in the clubs: Club president $(14.29 \%$, managing staff $-28.57 \%$, competent marketing department $-50.65 \%$, another function in the club-6.49\%).
Place

Big obstacle in improving the characteristics of the sports facilities is represented by the fact that the sports facilties are mostly property of local communities $(74.8 \%)$, sport and recreational centres $(16.2 \%)$, whereas only $6.3 \%$ of sports facilities belong to clubs. Such ownership structure of sports facilities complicates the process of improving the material and technical conditions in the sports facilities by the sports clubs management.

\section{Promotion}

Promotion in modern sport, as the element of the marketing mix, enables that everyone interested in sports clubs can be informed on their activities. Type of specificities of particular promotional means when it comes to promotional activities and campaigns in selected team sports is analysed in Table 4.

Table 4. Descriptive statistics on the promotion per team sports \%

\begin{tabular}{|c|c|c|c|c|c|c|c|c|}
\hline \multirow{2}{*}{ Promotion as the element of the marketing mix } & \multicolumn{2}{|c|}{ Football } & \multicolumn{2}{|c|}{ Basketball } & \multicolumn{2}{|c|}{ Handball } & \multicolumn{2}{|c|}{ Volleyball } \\
\hline & Yes & No & Yes & No & Yes & No & Yes & No \\
\hline Our promotional activity is effective. & 28.6 & 71.4 & 31 & 69 & 36 & 64 & 30 & 70 \\
\hline Is there a PR person working in the club? & 100 & 0 & 69 & 31 & 52 & 48 & 15.8 & 84.2 \\
\hline Does the club have its website? & 100 & 0 & 96.6 & 3.4 & 76 & 24 & 47.6 & 52.4 \\
\hline Does the club have its periodical? & 69.4 & 30.6 & 31 & 69 & 25 & 75 & 19 & 81 \\
\hline Is there a season guide? & 41.7 & 58.3 & 32.1 & 67.9 & 20 & 80 & 19 & 81 \\
\hline Does the club have the Media Day? & 34.3 & 65.7 & 24.1 & 75.9 & 20 & 80 & 4.8 & 95.2 \\
\hline Does the club have the Open Door Day? & 37.1 & 62.9 & 17.2 & 82.8 & 12 & 88 & 28.6 & 71.4 \\
\hline Is the club socially responsible? & 97.1 & 2.9 & 93.1 & 6.9 & 68 & 32 & 95.2 & 4.8 \\
\hline $\begin{array}{l}\text { Does the club have a sufficient number of volunteers } \\
\text { available? }\end{array}$ & 58.8 & 41.2 & 41.4 & 58.6 & 32 & 68 & 42.9 & 57.1 \\
\hline
\end{tabular}

Poor implementation of the marketing concept has determined the mostly identical opinion on its promotion efficiency. The result is around $30 \%$ in all sports, which only speaks that $70 \%$ of surveyed managers consider that the element of the marketing mix is very low in the clubs. Such result most obviously indicates the needs for a better conception of promotion within sports organisations, in order to have the clubs presentation better directed toward the interested population. Significance of public relations is most recognised in football and basketball (Table 4), whereas in volleyball there are fewest people dealing with PR activities (15.8\%). Accordingly, it can be observed that there are better capacities for adopting innovations in promotional activities in football and basketball thanks to the better position in the market and higher interest of all stakeholders. To support the aforementioned, there are data claiming that all clubs from the given sports have their own websites, as opposed to the handball and particularly, volleyball clubs. As for the periodicals, football clubs are most engaged about working with the media, which is expected due to their large audience. The club season guide, as the supporting means facilitating keeping up with the club activities throughout the competition year, is still not a widespread 
method of promotion in majority of team sports (up to 19 $25 \%$ in volleyball and handball and up to $30 \%$ of basketball clubs). Nevertheless, a little more than $2 / 3$ of football clubs is preparing their periodicals and providing information to all interested parties. Analysis of Table 4, gives information that numerous examinees (from $41.2 \%$ in football clubs up to $68 \%$ in handball clubs) believe that the clubs have insufficient number of available volunteers.

Moreover, results show the highest possible social responsibility in clubs, i.e. readiness to also be engaged in other spheres of life, outside competition activities. This can truly contribute to a more positive image of team sports in wider population, by expanding the significance, role and effects the competitive sports have on wider social community. Connection of sport and social responsibility and/or possibility of solving various social problems through engaging all people in the sports industry, can represent a good incentive for the reverse direction of care and contribution where the social community assists sports clubs in their functioning. Media Day and "Open" Day as the relatively new ways of organisational promotion are implemented in reduced scale. At the moment, these are somewhat "more active manners of promotion mostly implemented in football clubs $(1 / 3$ of clubs). Similar results have been obtained in regard to the season guides for the purpose of easier keeping up with the competition and other team activities, as well as sale of business tickets, where the football clubs are more engaged than others.

Differences in promotion per clubs, as the elements of the marketing mix, are presented in Table 5.

Table 5. Differences among various types of sports in promotion as the element of the marketing mix (Man-Whitney test)

\begin{tabular}{lccccc}
\hline & Football & Basketball & Handball & Volleyball & $\boldsymbol{X}^{\mathbf{2}}$ \\
\hline Our promotional activity is effective. & 32.14 & 32.93 & 22.25 & 23.60 & 0.39 \\
Is there a PR person working in the club? & $37.00^{2 \mathrm{aza} a \mathrm{a}}$ & $27.07^{3 \mathrm{a}}$ & 17.97 & $25.94^{3 \mathrm{~b}}$ & $41.51^{* *}$ \\
Does the club have its website? & $33.50^{3 \mathrm{a} 4 \mathrm{a}}$ & $32.38^{3 \mathrm{a} 4 \mathrm{~b}}$ & 19.95 & $26.48^{3 \mathrm{~b}}$ & $31.77^{* *}$ \\
Is there an official profile on the social networks? & $33.50^{3 \mathrm{a}}$ & $33.50^{3 \mathrm{a}}$ & 22.07 & $29.50^{3 \mathrm{a}}$ & $29.19^{* *}$ \\
Does the club have its periodical? & $38.57^{2 \mathrm{a} 3 \mathrm{a} 4 \mathrm{a}}$ & 26.09 & 22.29 & 23.63 & $20.06^{* *}$ \\
Is there a season guide? & 33.83 & 30.79 & 23.38 & 23.60 & 4.78 \\
Does the club have the Media Day? & $33.97^{3 \mathrm{~b}}$ & 30.72 & 21.60 & 25.10 & 6.66 \\
Does the club have the Open Day? & $35.39^{4 \mathrm{~b}}$ & 29.02 & 25.57 & 21.76 & 6.14 \\
Is the club socially responsible? & $33.09^{4 \mathrm{a}}$ & $31.79^{4 b}$ & $26.90^{4 b}$ & 20.64 & $15.07^{* *}$ \\
Does the club have a sufficient number of volunteers & $34.53^{4 \mathrm{~b}}$ & 29.03 & 24.86 & 22.36 & 4.52 \\
available? & & & & &
\end{tabular}

Note: ${ }^{*} 0.05,{ }^{* *}<0,01$ - Kruskal Wallis test; $1,2,3,4$ - 1 - football, 2 - basketball, 3 - volleyball, 4 - handball; $a<0.01, b<0.05$ Man Whitney test

These differences particularly indicate advantages of managers working in football and basketball when compared to the ones working in volleyball and handball and their higher stress on promotional values.
Finally, it is clear that the marketing strategy mostly relies on the internet, local/regional television and national newspapers as the most important promotional media in the sports clubs strategies (Figure 1).

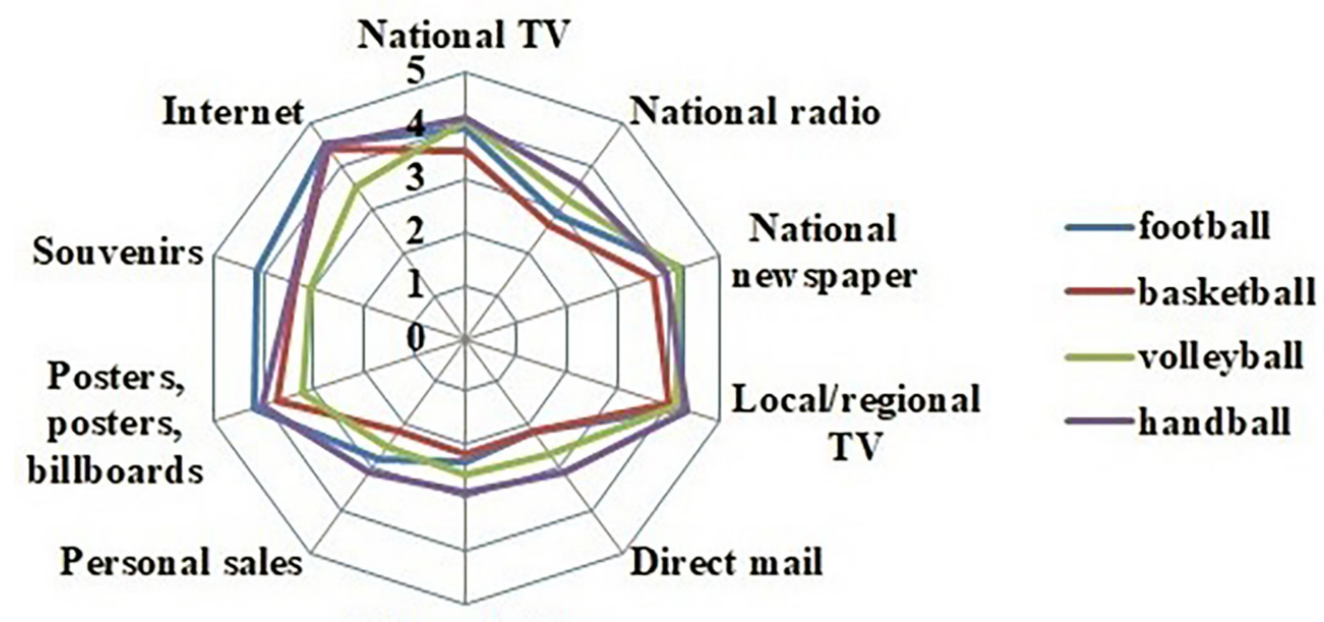

Telem arketing

Figure 1. How important or unimportant are the following promotional media in Your strategy?

\section{Distribution}

As in promotion, with respect to the element of distribution there are also statistically significant differences among football and other sports (Table 6), which can be ascribed to a somewhat better position favourable for commercialisation on the account of its popularity. 
Table 6. Differences between various types of Sports in distribution as element of marketing mix (Man-Whitney test)

\begin{tabular}{|c|c|c|c|c|c|}
\hline & Football & Basketball & Handball & Volleyball & $X^{2}$ \\
\hline Does the club sell business tickets? & $36.10^{2 \mathrm{a} 3 \mathrm{~b}}$ & 26.8 & 21.75 & 24.00 & $10.34^{*}$ \\
\hline Is the income higher based on the commercial activities? & $32.73^{4 b}$ & $32.22^{4 b}$ & 23.13 & 22.90 & $8.13^{*}$ \\
\hline
\end{tabular}

Note: ${ }^{*} 0.05,{ }^{* *}<0,01$ - Kruskal Wallis test; 1, 2, 3, 4 - 1 - football, 2 - basketball, 3 - volleyball, 4 - handball; $a<0.01, b<0.05-$ Man Whitney test

\section{Product}

Product quality to the highest point also determines all the other elements of the marketing mix. Figure 2, shows the elements composing the sports product. Volleyball clubs are to a highest degree satisfied with the quality of the national competitions, as well as with the conditions in which the clubs play their matches. Marketing potential of the clubs is, as expected, the highest in football and basketball clubs, but what is also interesting is the result showing that almost equally examinees in all sports consider that the marketing potential of the national competitions is very poor. Such result is the indicator that the clubs do not realise significant marketing effects in "creating" their own offer due to the insufficiently and poorly designed marketing concept of the national competition. In all sports, except in handball, examinees mostly believe that our clubs are in a more favourable position when compared to the ones from the former ex-Yugoslavian area. Higher values are recongised in the same sports with respect to the attitudes on the sports offer content. Human resoucres capacity suited on average the examinees in football and volleyball, and then in basketball and handball. Unlike human resources, clubs in all sports believe that they have low financial resources. Nevertheless, results in the basketball circles show a somewhat higher level of satisfaction when referring to this type of organisational resources.

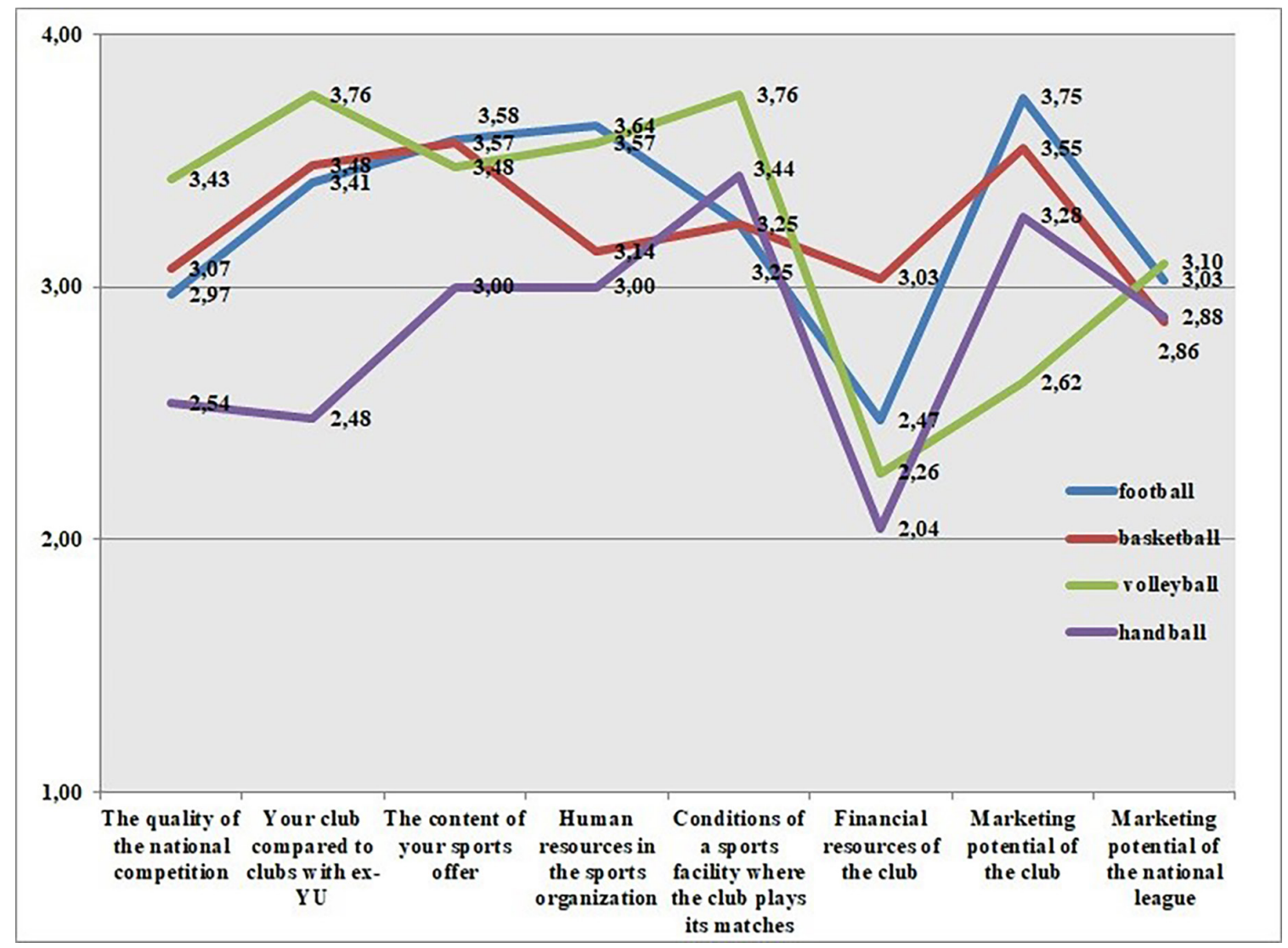

Note: 0-bad, 1-under average, 2-average, 3-above avarage, 4-excellent

Figure 2. Quality of certain elements of the sports offer of clubs per sports (AS)

\section{Discussion}

Low results speaking about the poor knowledge and implementation of the marketing concept in our team sports (except in examinees working in basketball), indicate the lack of marketing knowledge in examinees. The lack of marketing knowledge itself complicates formulation of personal marketing strategy, and/or development of their elements and thus better branding of sports organisations. It is interesting that the examinees recognise the needs of the specialised marketing department for further club development, but consider that there are poor chances for forming the marketing department in their clubs in the future. Week promotion is characterised by a small number of promotional activities (not marking the Media Day and "Open” Day, non-existence of the season guide, poor promotional activities on popular social networks, lack of websites, lack of engagement of PR persons (except in football), etc.). Furthermore, framework marketing mix show poor commercial activities and sale of business tickets having for a result low visit rates of spectators.

Poor sports offer provides limited marketing possibilities, which definitely partly justifies and not justifies the inactivity of marketing staff in sports organisations to consider all five levels of products in the target market, composing the hierarchy of 
values for purchasers: relevant benefit, basic, expected, enriched and potential product (Kotler \& Keller, 2006). Hence, it can be stated that what is referred to by the sports offer in Serbia are the "basic" and the "expected" product and/or what the purchaser customarily expects and accepts when buying the product. Unfortunately, possibilities and capacities relating to the "enriched" and potential" product including the purchasers' pleasure and through their the expectations and/or permanent modifications and innovations that the product might have in the future, stay outside the creativity domain making the sports events more appealing, attractive and the offer significantly more diverse.

Generally speaking, poorly "developed" marketing mix of our sports organisations "complicates" expansion of the potential market. This also reflects on the fact that marketing as the business function cannot develop its full potential. Sports offer of our sports organisations as the instrument of their marketing mix speaks about average products or services quality offered to sports consumers at more favourable prices, due to the perennial inability to modify the prices caused by the difficult economic conditions required for functioning.

Quality of sports profucts offered at the sports events within the domestic competitions is all the less attractive and insufficiently appealing to potential consumers of sports products (Maksimović, Matić, Milošević, Jakšić, Shreffler, Ross, 2012). All of the aforementioned speaks in favour of the quality of sports products offered by our clubs in the sports market of Serbia monitored in the decline and stagnation trends. Spectators follow the matches of their clubs more intensely in international competitions than in domestic competitions, which is the indicator of greater attachment during larger sports events, i.e. loyalty to clubs is the prominent trait in our local audience on more significant games. Necessity of identification with successful teams imposes achieving continuously good results. Namely, sports comsumers offer verification of good sports competitiveness in the international competitions among clubs and accordingly, there is higher interest during the season for the international matches.

According to Žnideršić, Grubor, Salai, \& Marić (2012), the key reason is found in the fact that the "new" consumer is by far mor einformed, sophisticated and demanding which enables success of companies redy to adjust to the new requirements. Likewise, there is a growing number of laws and other types of consumer protection working in favour of their satisfaction and loyalty, which repeatedly indicates the central role taken by the modern conumer in the global environment". Business or marketing orientation toward the consumers suggest that the busuiness is started where purchasers are, and not where the seat of the sports organisations and sports facilities are. It is necessary to examine the needs of the domestic sports market (existing and "new"), do the segmentation, "create" a differentiated offer, and then make a move in pleasing the largest part of their needs. Therefore, if considering the Kotler's product definition as "everything which can be offered in the market, in order to please a specific wish or need", it can be concluded that the wishes and needs of our consumers are much bigger than the possibilities of the Serbian offer which can be offered by our clubs, which explains a poorly developed consumer behaviour in team sports.

Elements offered by product, sales, marketing and social marketing concept are definitely applicable on our market. By following the principles of the sales concept, sports organisati- ons should head toward the consumers of their "goods", whereas the the successful experiences of many sports organisations impose placement of consumers in the most significant position with all employees by forming the sports offer, by applying the marketing and social marketing concepts. Implementation of the principle actually requires harmonisation of current resources of sports organisations. If assessing the possibilities and/or the marketing mix elements on which the clubs can base their development strategy, these are the staff, promotion, price and the product. Having in mind that the element "place" i.e. venues of the sports events are mostly outdated, one can surely not rely on their soon adaptation. What is enabled can mostly be limited on their transparency, history and memories of important games played on them, followed by the fact that all other elements of the venues are average or below average. Moreover, ownership structure is unfavourable for the strategic plans of sports facilities development by the management of sports organisations, comnsidering that only $6.3 \%$ of sports clubs own their own sports facility. Current condition of the Serbian sport requires more prominent investments in the Serbian infrastructure, in accordance with the consumers' needs with an adequate development of economy and the society in general.

Therefore, the results obtained in this research are in accordance with the ones emphasised by Maksimović and Raič (2007) claiming that "marketing in sports overcomes undesirable perception "blindness" of changeable social, economic, technological, cultural, political and other circumstances reelvant for the development, survival and temrination of sports organisations". The role of organising the existing marketing mix through the marketing function (plan, implementation, control, anaylsis) and harmonise it with demographic, economic and political factors, should be played by the marketing managers in domestic sports organisations. Furthermore, obtained results are in line with the studies implemented by the authors Vojinović, Maksimović, Koković, Raič, Matić and Doder (2015), which discovered "a difficult to understand lack of interest of the sports infrastructure (branch unions, local administration) for creating organisational culture in our sport, supporting creativity in the field of converging the vision of future sport and its democratic way of articulation through the scenario of planning and developing strategies of sustainable development of sports in the European surroundings."

All of the aforementioned in the discussion shows major dependency of the contemporary sports organisations from marketing - market researches (audience, membership and fans, sponsors, media) and finding effective strategies (marketing mix). Organisations which fail at implementing the marketing concept in their management, manifest less success - business, socio-political, but also sports-competitive. According to this statement, what is clear is the indication that the future of the sports clubs is directly focused on the marketing concepts. Based on this, according to all the obtained indicators presented in the dissertation, response to the following question can at least partly be found: How to introduce, implement and improve the management marketing concept in the sports clubs across Serbia? The following essential tasks of the marketing sector come as predominant ones: 1) brand management, 2) influence on increasing the number of views at the matches, 3 ) increased activities in obtaining and managing the sponsor pool, 4) increasing the possibilities for TV rights management, 5) commercialisation of the protected trademarks through selling designer products and licensing. 
The exact identification and orientation toward the marketing concept as to the powerful business means of numerous successful organisations, focusing the center of their attention on the current and future consumers, would contribute so that the organisations which have denied their major significance, would accept the concept in question. These influences could contribute to placing the entire management of the sports clubs on the pedestal of the marketing concept.

\section{Acknowledgements}

There are no acknowledgements.

\section{Conflict of Interest}

The authors declare that there are no conflicts of interest.

Received: 18 April 2019| Accepted: 28 May 2019| Published: 4 July 2019

\section{References}

Andreff, W. (2001). The Correlation Between Economic Underdevelopment and Sport. European Sport Management Quarterly, 1(4), 251-279.

Borden, N. H. (1964). The concept of the marketing mix. Journal of Advertising Research, 4, 2-7.

Gašović, M. (2005). Definisanje sportskog marketinga [Definition of sports marketing]. Anali Ekonomskog fakulteta u Subotici, 14, 117-122.

Gašović, M. (2009). Marketing sportskih organizacija (trans. Marketing of sports organizations). Belgrade: IntermaNet.

Gašović, M. (2011). Marketing istraživanje za potrebe organizatora sportskih događaja [Marketing research for the needs of organizers of sports events]. Marketing, 43(2), 133-140.

Grubor, A. (2009). Stvaranje vrednosti u marketingu usluga [Creating
Value in Services Marketing]. Ekonomske teme, 3, 43-55.

Grubor, A. (2010). Marketing i uslužna ekonomija [Marketing and Service Economy]. Ekonomske teme, 4, 531-545.

Jobber, D. (2006). Osnovi marketinga (trans. Fundamentals of marketing). Belgrade: Data status.

Kotler, P., Keller, K. L. (2006). Marketing menadžment (trans. Marketing management). Belgrade: Data Status.

Maksimović, N., Matić, R., Milošević, Z., Jakšić, D., Shreffler, M., Ross, S. (2012). Motives and identification of different types of fans with a team in Serbian soccer. TTEM, 7(1) 39-48.

Maksimović, N., \& Raič, A. (2012). Sportski menadžment (trans. Sports management). Novi Sad, Serbia: Faculty of Sport and Physical Education.

Milne, G.R., \& McDonald, M.A. (1999). Sport marketing: Managing the exchange process. Sudbury, MA: Jones and Bartlett Publishers.

Mullin, B. J, Hardy, S. \& Sutton, W. A. (2007). Sport Marketing - 3rd(ed.). Champaign: Human Kinetics.

Popovic, S. (2017). Contemporary Sports Product and Making a Brand. Exercise and Quality of Life, 9(1), 37-41.

Shilbury, D., Westerbeek, H., Quick, S., \& Funk, D. (2009). Strategic Sport Marketing, 3rd edition. Sydney: Allen \& Unwin.

Tomić, M. (2001). Marketing u sportu (trans. Marketing in sport). Belgrade: Astimbo.

Vojinovic, J., Maksimovic, N., Kokovic, D., Raic, A., Matic, R., \& Doder, D. (2015). Predicting the future of sports organizations. Motriz, 21(2), 107-115.

Žnideršic Kovac, R., Grubor, A., Salai, S., \& Maric, D. (2012). Knowledge as the power of new consumers in the global environment. Celje: International Conference MakeLearn 2012. Obtained on 24 September 2012 from: http://www.issbs.si/press/ISBN/978-961-6813-10-5/ papers/ML12_121.pdf 